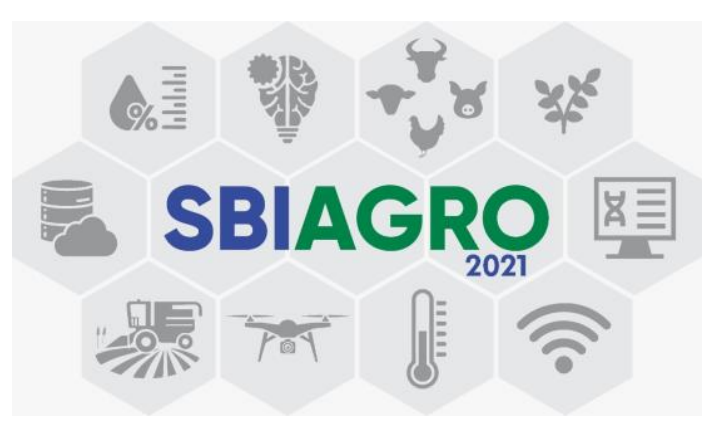

\title{
IrrigaFeijão - Software para Manejo da Irrigação do Feijoeiro
}

\author{
Pedro M. Silveira ${ }^{1}$, Marcelo G. Narciso ${ }^{1}$, Alexandre B. Heinemann ${ }^{1}$, Silvando C. \\ Silva ${ }^{1}$, Fábio F. Noleto ${ }^{1}$, Luiz F. Stone ${ }^{1}$, \\ ${ }^{1}$ Embrapa Arroz e Feijão - Fazenda Capivara \\ - 74.501-970 - Goiânia - GO - Brasil
}
\{pedro.marques, marcelo.narciso, alexandre.heinemann, silvando.silva, fabio.noleto, luis.stone\} dembrapa.br

Abstract. To avoid loss of productivity in the bean plant, due to inadequate water supply for the plant, planned irrigation is important, in order to irrigate only what is necessary for the bean plant to develop and have the highest possible productivity. In this context, in the case of central pivot irrigation, there is a software for the bean crop, IrrigaFeijão, which allows planning irrigation throughout the plant cycle and with the minimum daily amount of water needed for growth healthy bean plant.

Resumo. Para evitar a perda de produtividade do feijoeiro, por fornecimento inadequado de água para a planta, é importante uma irrigação planejada, de forma a irrigar somente o necessário para o feijoeiro se desenvolver e ter a maior produtividade de grãos. Neste contexto, para o caso da irrigação ser por pivô-central, existe um software, para a cultura de feijão, o IrrigaFeijão, que permite quantificar a água necessária para o desenvolvimento da planta.

\section{Introdução}

O feijão é uma cultura de ciclo curto, por isso pode ser muito afetada pela deficiência hídrica. A primeira safra de 2020, por exemplo, sofreu com a estiagem e teve impactos na sua produtividade [IRRIGA 2021].

A irrigação é uma tecnologia que permite planejar melhor a lavoura e não contar somente com a "sorte" da chuva na hora certa. Assim, é importante um planejamento da irrigação. 
O manejo da irrigação no feijoeiro consiste em aplicar água na cultura no momento adequado e em quantidades apropriadas. Isso é importante, visto que a produtividade de grãos da cultura é afetada pela condição hídrica do solo. Deficiência ou excesso de água reduz a produtividade em diferentes proporções.

Para facilitar o manejo da irrigação em uma lavoura de feijão, foi construído um software web para a irrigação do feijoeiro, por meio do pivô central, para o Estado de Goiás e alguns minicípios de MG, SP e MT, em sua versão inicial. Este software, cujo nome é IrrigaFeijão, mostra um calendário no qual tem a quantidade de água a ser irrigada em cada dia, de forma a suprir as necessidades de água da planta. O calendário tem início no momento do plantio, e a duração do calendário é conforme o ciclo vegetativo da planta, que pode ser 80, 90 ou 100 dias, e sob plantio direto.

O sistema foi implementado para irrigação por pivo-central, visto que quase a totalidade de irrigação do feijão é feita por esse sistema, como pode ser visto em [AGEITEC 2021]. A Figura 1, a seguir, ilustra um pivô central irrigando uma lavoura de feijão.

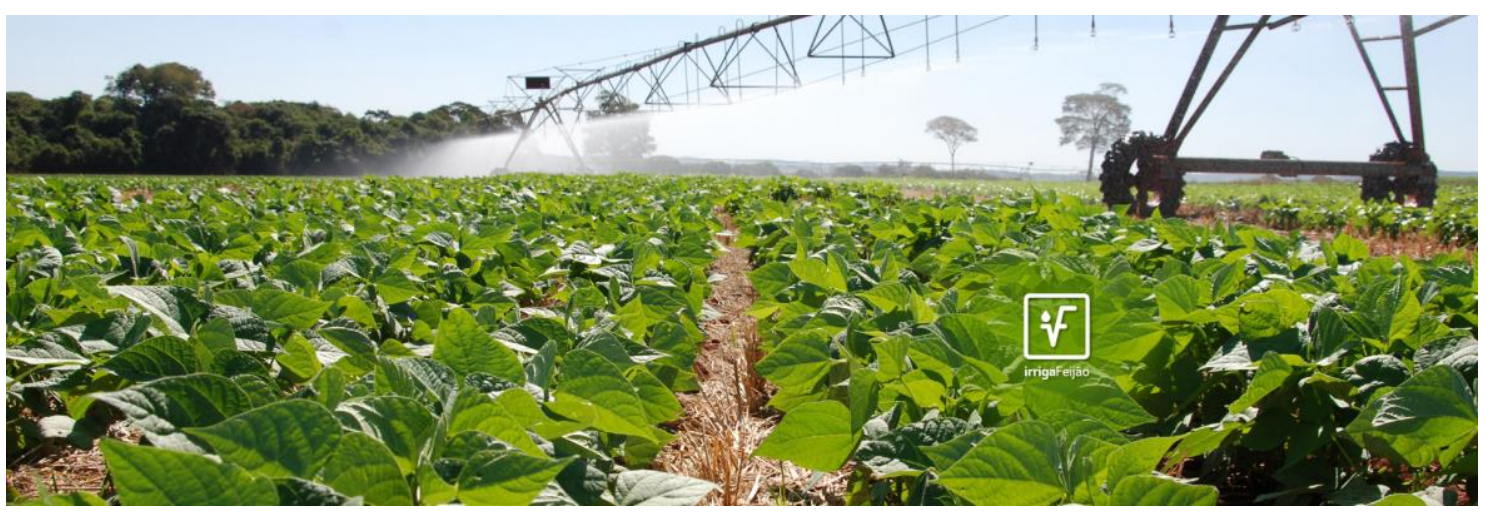

Figura 1. Irrigação de lavoura de feijão por pivô central.

Este artigo descreve o software IrrigaFeijão como ferramenta para o manejo da irrigação via pivô-central, com acesso pela web pelo link www.cnpaf.embrapa.br/irrigaFeijao.

\section{Material e Métodos}

O IrrigaFeijão foi construído para o Estado de Goiás e alguns municípios de SP, MG e MT. Para isto, foram necessários dados de estádio e coeficientes de cultura $(\mathrm{Kc})$ do feijoeiro, para 80. 90 e 100 dias, e de evapotranspiração de referência (ETo) para cada dia durante o ciclo da cultura e para cada município considerado. Os dados relativos a ETo foram provenientes do estudo realizado por Xavier et al. (2016), e estes dados foram de 1980 a 2013. Estes dados foram retirados da base de dados do sistema Infoclima, que pode ser visto em [Infoclima 2021], e anexados à bade de dados do sistema IrrigaFeijão. Com estes 33 anos de dados, foi feita uma média para cada dia e para cada município, para que o sistema IrrigaFeijão tivesse todos os dados de ETo. O coeficiente de cultura (Kc) foi obtido pela relação entre a evapotranspiração da cultura (ETc) e a evapotranspiração de referência (ETo). Os dados de Kc foram obtidos experimentalmente na Embrapa Arroz e Feijão e podem ser vistos em [KC 2021]. Através desse coeficiente, 
Kc, e conhecendo-se a ETo de um feijoeiro, pode-se estimar a lâmina de irrigação diária a ser aplicada. Para um dado dia i, o valor da lâmina a ser aplicada é igual a

$$
\text { lâmina }_{\mathrm{i}}=\mathrm{kc}_{\mathrm{i}} * \mathrm{ETo}_{\mathrm{i}}
$$

O motivo do sistema ter 33 anos de dados, para cada dia do ano e por município, é para se ter uma média, para todos os dias do ano, de ETo, o qual é calculado pela fórmula de Penman-Monteith, a partir da temperatura e umidade do ar, velocidade do vento e radiação solar [PM 2006]. Com isso, é possível prever o quanto irrigar em qualquer dia do ano, a partir do dia atual (hoje). Por exemplo, se o plantio for começar em um dado dia e mês, é possível ver o quanto irrigar a partir daquela data inicial até ao final do ciclo da planta. Então, é possível saber quanto vai ser o gasto médio de água em todo o ciclo de cultivo feijoeiro antes de iniciar o plantio.

O sistema tem com entrada de dados o local da lavoura (município), o dia inicial do plantio, o ciclo vegetativo da planta (80, 90 ou 100 dias), a eficiência de distribuição de água do pivô ( $80 \%$ ou $85 \%$ ) e sua lâmina de água aplicada a $100 \%$ do percentímetro. Ao ler estes dados, o sistema monta uma tabela de irrigação, a partir do dia inicial de plantio, até ao final do ciclo escolhido, calcula o quanto de água foi consumido pela planta e estabelece o quanto deve ser reposto, em cada dia do ciclo, e insere estes dados na planilha de saída do sistema, a qual pode ser salva ou impressa.

O sistema web foi feito com as linguagens javascript e PHP, além de HTML 5 e CSS. A base de dados do sistema foi feita usando o SGBD Mysql. O Aplicativo Dr Feijão, que está no google Play (Android) e App Store (IOs), contém a versão mobile do sistema IrrigaFeijão.

\section{Resultados}

O sistema IrrigaFeijão possui um menu, e este direciona o usuário a escolher as páginas que explicam como o sistema funciona, além de considerações sobre o manejo da irrigação do feijoeiro. É recomendado que o usuário leia estas páginas antes de entrar com os dados no sistema. Na página relativa à entrada de dados, existe um formulário, com informações a serem preenchidas. Este formulário é a entrada de dados do sistema, o qual é ilustrado na Figura 2. 


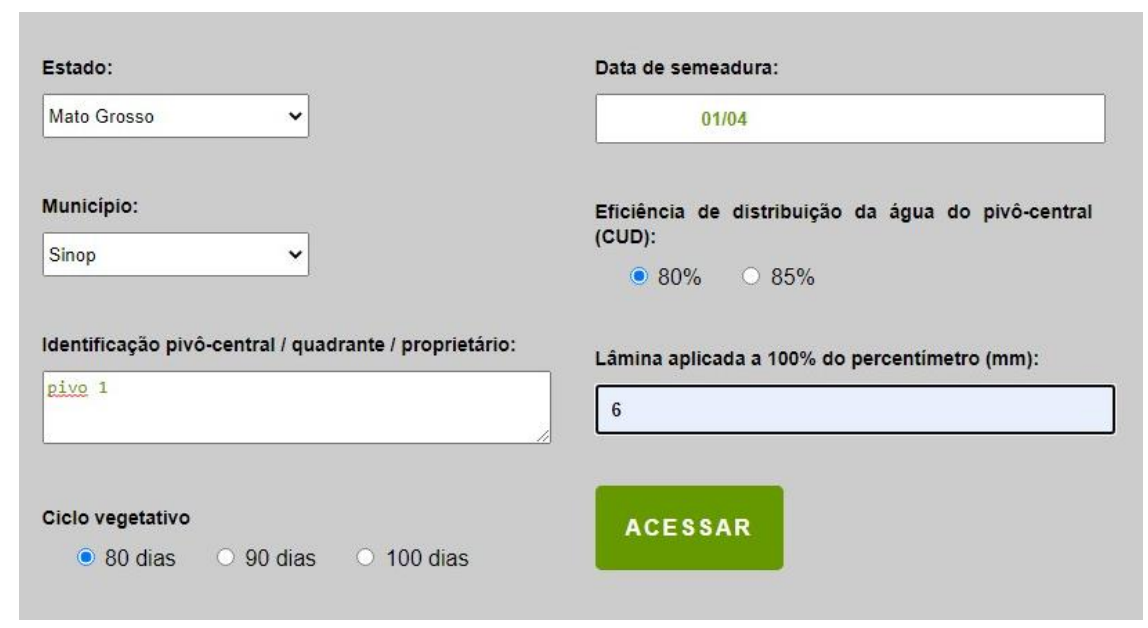

Figura 2. Formulário de entrada de dados do sistema IrrigaFeijão

Este formulário contém campos a serem preenchidos. O município deve ser escolhido para então o sistema obter os valores de ETo corretos para o cálculo da lâmina de irrigação. O ciclo vegetativo é usado para se escolher os valores de Estádio e Kc (coeficiente da cultura) correspondentes a 80, 90 ou 100 dias. A data de semeadura é importante para escolher ETo a partir desta data até ao final do ciclo. É a partir desta data que os cálculos começam e são mostrados na planilha, que está na Figura 3. A eficiência de distribuição de água ( $80 \%$ ou $85 \%$ ) é usada para o cálculo da lâmina de água a ser aplicada da seguinte forma, para i-ésimo dia:

lâmina $_{\mathrm{i}}=\mathrm{kc}_{\mathrm{i}} *$ Eto $_{\mathrm{i}} /$ eficiência, onde eficiência é igual a 0.80 ou 0.85 .

O valor da lâmina aplicada a $100 \%$ do percentímetro (mm) é usado para calcular o valor do percentímetro do pivô central, em \% para cada aplicação da lâmina de água, conforme ilustrado na Figura 3.

Após inserir e submeter os dados, o sistema irá mostrar a planilha de irrigação, tal como ilustra a Figura 3. 


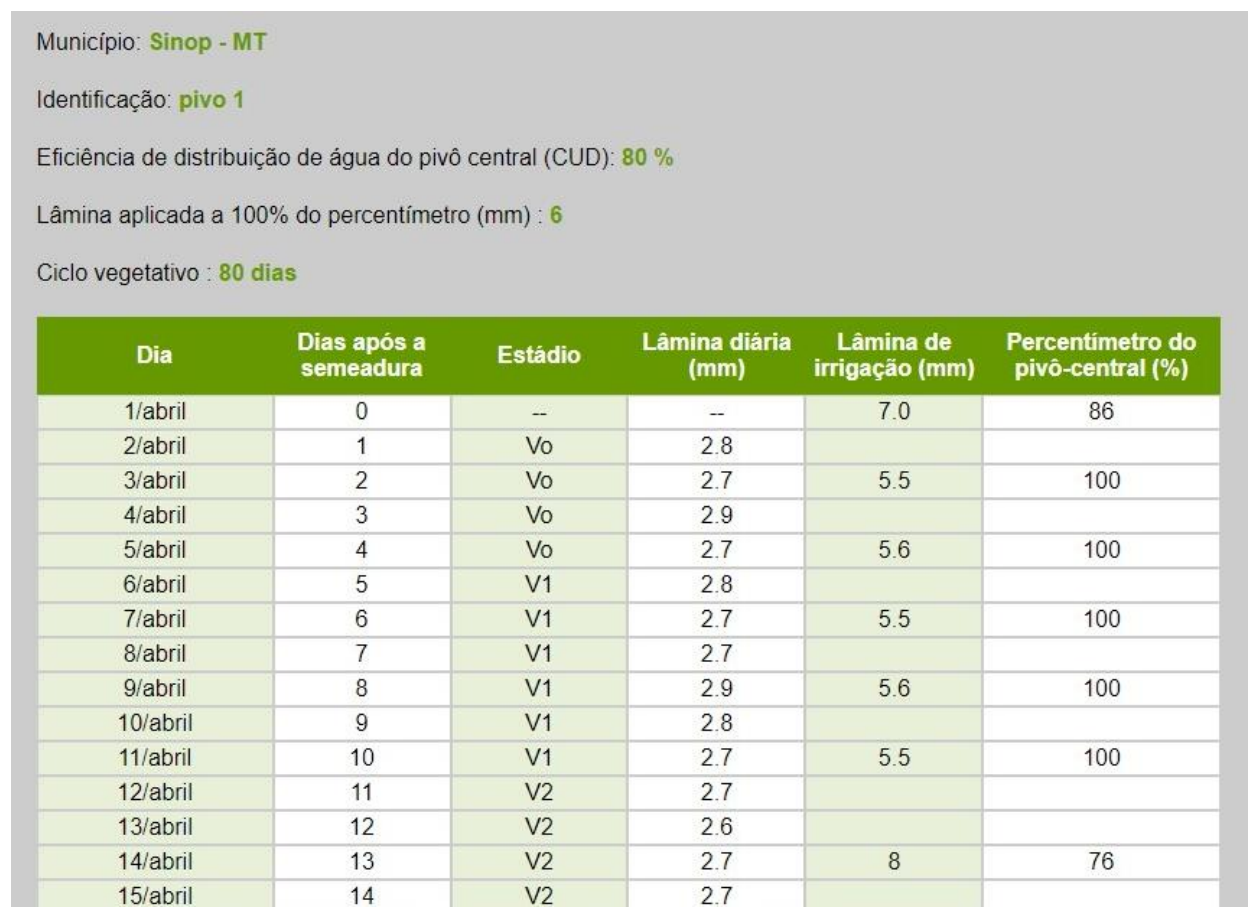

Figura 3. Planilha de saída de dados do sistema IrrigaFeijão

Conforme ilustrado na Figura 3, foram considerados Turnos de Rega de 2 dias na fase inicial (as raízes ainda estão pequenas) e de 3 dias no restante do ciclo da cultura. $\mathrm{Na}$ definição do Turno de Rega de 3 dias, levou-se em consideração a capacidade de retenção de água dos solos do Cerrado, como também fatores inerentes ao tamanho da área de irrigação.

Ocorrendo chuva entre a última irrigação e a próxima (duas irrigações consecutivas), a quantidade da precipitação pluvial, em mm, medida por pluviômetro instalado próximo à área, deve ser subtraída da lâmina de água da próxima irrigação. Se essa precipitação pluvial for maior que a lâmina da próxima irrigação, considerar essa irrigação já atendida e não computar créditos dos milímetros $(\mathrm{mm})$ de água excedentes em irrigações futuras.

Esta planilha foi elaborada para semeadura variando de 01 de abril a 20 de junho, época apropriada para semeadura de feijão de terceira safra (feijão irrigado). A Figura 4 ilustra o final da planilha, que vai até o final do ciclo da cultura. 


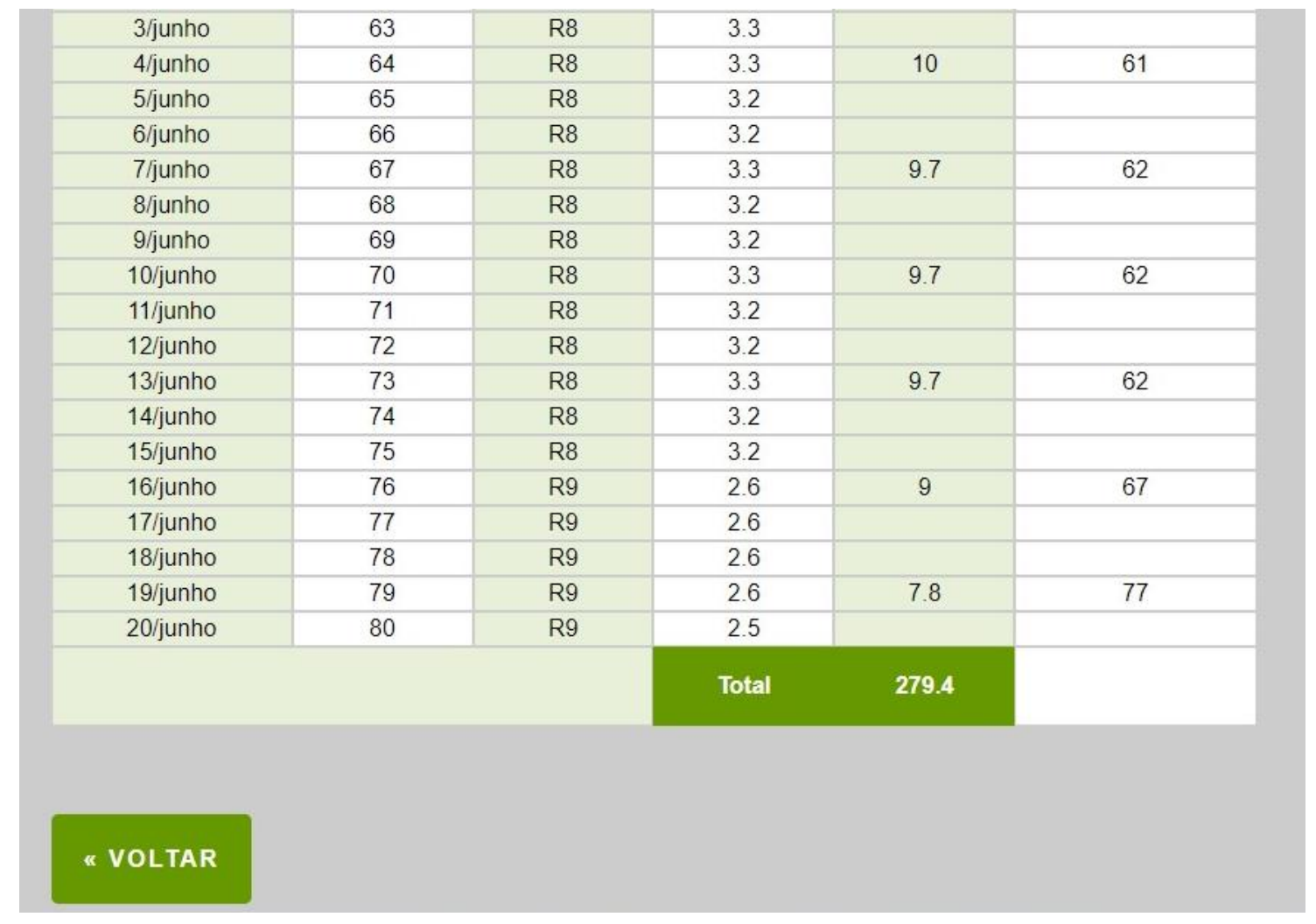

Figura 4. Planilha de saída de dados do sistema IrrigaFeijão, Valores finais da planilha.

\section{Comentários finais}

Neste contexto de planejamento e uso da irrigação, por pivô central, está o IrrigaFeijão. É um software fácil de usar, e que reúne as variáveis necessárias para auxiliar, de maneira simples e prática, o usuário a realizar o planejamento/manejo da irrigação na cultura do feijão, por pivô central, em Goiás e alguns municípios produtores de feijão de MT, MG e SP. Vale a pena ressaltar que, para a cultura do feijão, o sistema foi implementado para irrigação por pivo-central visto que quase a totalidade de irrigação do feijão é feita por esse sistema.

O planejamento/manejo apresenta-se na forma de um calendário de irrigação, com informações de quando e quanto irrigar, após o usuário informar o município, a data prevista de semeadura, a eficiência do pivô central e a lâmina mínima aplicada. Portanto, o IrrigaFeijão é um software de apoio a decisão, que aconselha o usuário quando e quanto irrigar.

Assim, os usuários que não dispõem de outro método de manejo da irrigação do feijoeiro na lavoura têm no no IrrigaFeijão uma planilha de planejamento prático da irrigação da cultura, a partir da data de semeadura, de modo fácil e rápido e com precisão aceitável. 
O IrrigaFeijão pode ser adpatado para outros culturas que usam pivô central para irrigação. Para isto, basta saber o valor de Kc para a cultura específica que se desejar planejar/manejar a irrigação.

A quase a totalidade dos irrigantes não usam nenhum metodo de controle. $\mathrm{O}$ irrigafeijão vem atender essa demanda.

\section{Referências Bibliográficas}

AGEITEC. Sítio disponível em https://www.agencia.cnptia.embrapa.br/gestor/feijao/arvore/CONTAG01_86_13112002 15104.html. Sítio visitado em 07/09/2021.

Infoclima, Sítio disponível em www.cnpaf.embrapa.br/infoclima. Sítio visitado em 07/09/2021.

IRRIGA. Sítio disponível em https://blog.aegro.com.br/irrigacao-de-feijao/. Sítio visitado em 07/09/2021.

KC. Sítio disponível em https://www.agencia.cnptia.embrapa.br/gestor/feijao/arvore/CONTAG01_86_13112002 15104.html, Sítio visitado em 07/09/2021.

MP. Sítio disponível em

https://ainfo.cnptia.embrapa.br/digital/bitstream/CNPUV/8815/1/cir065.pdf Sítio visitado em 07/09/2021.

Xavier, A. C.; King, C. W.; Scanlon, B. R. Daily gridded meteorological variables in Brazil: (1980.2013). International Journal of Climatology, v. 36, n. 6, p. 2644- 2659, mar. 2016. 